\title{
Sensitivity of Colletotrichum Isolates Collected from Strawberries in Georgia to Pyraclostrobin, a Quinone Outside Inhibitor (Qol) Fungicide
}

\author{
Md Emran Ali, ${ }^{1,+}$ Owen Hudson, ${ }^{1}$ Sumyya Waliullah, ${ }^{1}$ Jeff Cook, ${ }^{2}$ and Phillip M. Brannen ${ }^{3}$ \\ ${ }^{1}$ Department of Plant Pathology, University of Georgia, Tifton, GA 31793 \\ ${ }^{2}$ University of Georgia Cooperative Extension, Peach County, Wing A, Fort Valley, GA 31030 \\ ${ }^{3}$ Department of Plant Pathology, University of Georgia, Athens, GA 30602
}

Accepted for publication 24 January 2020.

Keywords: Colletotrichum spp., fungicide, pyraclostrobin, strawberry, small fruit, resistance

Anthracnose fruit rot disease, caused by Colletotrichum acutatum, is the most significant disease problem of commercial strawberry $($ Fragaria $\times$ ananassa) production in the southeastern United States (Maas 1998). Fruit rot with dark, sunken lesions is the main symptom of this disease (Peres et al. 2005). The hot, humid weather and continuous rainfall in Georgia make Colletotrichum-induced fruit rot a widespread problem in strawberry production. For controlling this disease, growers mainly rely on preventive fungicide applications from flower bud emergence to harvest. The most commonly used single-site fungicides are quinone outside inhibitors (QoIs); the QoI active ingredients azoxystrobin and pyraclostrobin are utilized to manage anthracnose fruit rot (Turechek et al. 2006). If appropriate resistancemanagement strategies are not implemented, QoIs are at increased risk of resistance development and subsequent control failure (Forcelini et al. 2016). The QoIs have been marketed since 1996, and resistance development is expected with long-term use, but limited surveys and in vitro efficacy tests conducted in 2004 and 2008 did not confirm QoI resistance (P. M. Brannen and K. L. Stevenson, personal communication). However, more recently, producers have complained of failure to control when using QoI fungicides, and resistance had been confirmed in one Georgia site (Forcelini and Peres 2018). Based on mycelial growth of Colletotrichum acutatum isolates, a recent study showed the effective concentrations necessary to inhibit 50\% growth $\left(\mathrm{EC}_{50}\right)$ values ranged from 0.110 to $10 \mu \mathrm{g} / \mathrm{ml}$ for pyraclostrobin (Forcelini et al. 2016). In 2019, we collected 108 strawberry fruits with visible rot symptoms from seven different strawberry farms in Georgia. These farms had received multiple applications of QoI fungicides during the 2019 growing season, as well as in previous seasons. Symptomatic fruit was cut in half with a sterile scalpel, and a small specimen plug was taken from the margin of individual lesions and directly inoculated onto prepared plates of acidified quarter-strength potato dextrose agar. The plates were incubated for 5 days at $22^{\circ} \mathrm{C}$, and the initial identity of the isolates was confirmed based on the morphological features of the conidial shape, size, and other distinguishing characteristics. Acervuli produced conidia with acute ends that were consistent with the $C$. acutatum species complex (Damm et al. 2012;

${ }^{\dagger}$ Corresponding author: M. E. Ali; emran.ali@uga.edu

The author(s) declare no conflict of interest.

(C) 2020 The American Phytopathological Society
Gunnell and Gubler 1992; Leandro et al. 2001). In addition to comparison of morphological characteristics, 20 randomly selected isolates from 108 Colletotrichum spp. were further verified via PCR amplification using Colletotrichum species-specific primers acut1 (5'CCGGAGGAAACCAAACTCTATTTAC-3') and col2 (5'-TTACTACGCAAAGGAGGCT-3') from the ribosomal DNA internal transcribed spacer region (Martinez-Culebras et al. 2003). The PCR conditions included an initial denaturation step at $94^{\circ} \mathrm{C}$ for $5 \mathrm{~min}$, followed by 34 cycles of $94^{\circ} \mathrm{C}(30 \mathrm{~s}), 56^{\circ} \mathrm{C}(30 \mathrm{~s})$, and $72^{\circ} \mathrm{C}(60 \mathrm{~s})$, and a final extension step at $72^{\circ} \mathrm{C}$ for $6 \mathrm{~min}$ in a BioRad T1000 thermocycler using EconoTaq plus green $2 \times$ master mix (Lucigen, Middleton, WI) following a protocol suggested by the supplier. Our results showed that all 20 isolates collected from infected fruit tissue were $C$. acutatum. Although we did not confirm species identification for all isolates through the use of molecular techniques, colony morphology was similar across all isolates, and they were likewise assumed to be C. acutatum isolates.

Sensitivities to pyraclostrobin (Cabrio, BASF, Research Triangle Park, NC) were assessed on $1 \%$ malt extract agar (10 g of malt extract and $15 \mathrm{~g}$ of agar) using a mycelial growth inhibition assay as described previously by Ali et al. (2019). For each isolate, two mycelial plugs were taken from the edge of an actively growing 10day-old colony and were transferred upside down at the centers of pyraclostrobin fungicide-amended plates at concentrations of $100 \mu \mathrm{g} / \mathrm{ml}$ and nonamended control plates. Salicylhydroxamic acid was added to the fungicide solution, and treatments were replicated three times. Plates were incubated for 5 days at $22^{\circ} \mathrm{C}$ before measuring the radial growth in two perpendicular directions and determining fungicide sensitivity. Four plates were used for each isolate, and sensitivity tests were repeated twice. Four key relative growth inhibition (RGI) categories were utilized to evaluate isolate sensitivity to pyraclostrobin: (i) RGI for resistance, no or $<15 \%$ growth inhibition; (ii) RGI for moderate resistance, 15 to $50 \%$ growth inhibition; (iii) RGI for reduced sensitivity, 51 to $75 \%$ growth inhibition; and (iv) RGI for sensitive isolates, $>75 \%$ growth inhibition. Based on these parameters, the percentage of resistant, moderately resistant, reduced sensitivity, and sensitive isolates were $47,42,8$, and $3 \%$, respectively (Table 1). Our results demonstrated that a majority of Colletotrichum isolates collected in 2019 were not inhibited by pyraclostrobin, suggesting a growing resistance issue with the QoI fungicides. 


\section{TABLE 1}

$\begin{aligned} & \text { Sensitivity of Colletotrichum isolates collected from Georgia } \\ & \text { to pyraclostrobin, a quinone outside inhibitor (Qol) }\end{aligned}$

${ }^{\mathrm{a}} \mathrm{RGI}=$ relative growth inhibition .

A recent report indicated that resistance to QoIs has been associated with the presence of an amino acid substitution G143A in the cytochrome $b$ gene (Forcelini et al. 2018). For further confirmation of the pyraclostrobin resistance phenotype, we examined all 108 isolates for the presence of the G143A substitution using the PCR-restriction fragment length polymorphism assay as described by Forcelini et al. (2016). In brief, PCR products amplified from $C$. acutatum isolates using cytb-specific primers (C.gramcytb-bf1/ C.gramcytb-br1) were digested with $A l u \mathrm{I}$ and separated on a $2 \%$ agarose gel. Our results showed the presence of the G143A mutation in all QoI-resistant C. acutatum isolates and $87 \%$ of isolates with moderate resistance, but none with reduced sensitivity or sensitive isolates (Table 1). These results further prove that $C$. acutatum isolates with the G143A mutation are highly resistant to the QoI fungicide pyraclostrobin; cross-resistance is readily observed across QoIs, so azoxystrobin will likely have no activity against isolates with the G143A mutation as well. These findings suggest that there is a high risk of resistance development associated with using pyraclostrobin (likely all QoIs) for controlling anthracnose fruit rot of strawberry disease in Georgia. For effective control of this disease, growers need to focus on using multisite fungicides and alternation with classes other than QoIs. Going forward, growers should have their anthracnose populations tested for QoI resistance, and the use of QoIs may be limited in future management strategies as a result of widespread resistance development.

\section{Literature Cited}

Ali, M. E., Hudson, O., Hemphill, H. W., Brenneman, B. T., and Oliver, E. J. 2019. First report of resistance to pyraclostrobin, boscalid, and thiophanatemethyl in Colletotrichum gloeosporioides from blueberry in Georgia. Plant Health Prog. 20:261-262.

Damm, U., Cannon, P. F., Woudenberg, J. H. C., and Crous, P. W. 2012. The Colletotrichum acutatum species complex. Stud. Mycol. 73:37-113.

Forcelini, B. B., and Peres, N. A. 2018. Widespread resistance to QoI fungicides of Colletotrichum acutatum from strawberry nurseries and production fields. Plant Health Prog. 19:338-341.

Forcelini, B. B., Rebello, C. S., Wang, N. Y., and Peres, N. A. 2018. Fitness, competitive ability, and mutation stability of isolates of Colletotrichum acutatum from strawberry resistant to QoI fungicides. Phytopathology 108: 462-468.

Forcelini, B. B., Seijo, T. E., Amiri, A., and Peres, N. A. 2016. Resistance in strawberry isolates of Colletotrichum acutatum from Florida to quinoneoutside inhibitor fungicides. Plant Dis. 100:2050-2056.

Gunnell, P. S., and Gubler, W. D. 1992. Taxonomy and morphology of Colletotrichum species pathogenic to strawberry. Mycologia 84:157-165.

Leandro, L. F. S., Gleason, M. L., Nutter, F. W., Jr., Wegulo, S. N., and Dixon, P. M. 2001. Germination and sporulation of Colletotrichum acutatum on symptomless strawberry leaves. Phytopathology 91:659-664.

Maas, J. L. 1998. Compendium of Strawberry Diseases. APS Press, St. Paul, MN.

Martinez-Culebras, P. V., Querol, A., Suarez-Fernandez, M. B., Garcia-Lopez, M. D., and Barrio, E. 2003. Phylogenetic relationships among Colletotrichum pathogens of strawberry and design of PCR primers for their identification. J. Phytopathol. 151:135-143.

Peres, N. A., Timmer, L. W., Adaskaveg, J. E., and Correl, J. C. 2005. Lifestyles of Colletotrichum acutatum. Plant Dis. 89:784-796.

Turechek, W. W., Peres, N. A., and Werner, N. A. 2006. Pre- and post-infection activity of pyraclostrobin for control of anthracnose fruit rot of strawberry caused by Colletotrichum acutatum. Plant Dis. 90:862-868. 